\title{
Determinants of Generalized Anxiety, Depression, and Subjective Sleep Quality among University Students during COVID-19 Pandemic in Bangladesh
}

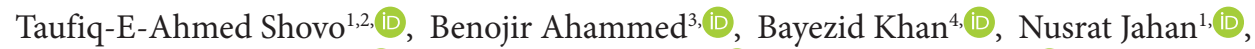 \\ Tunvir Ahamed Shohel ${ }^{1,5,(\mathbb{D},}$, Md. Tanvir Hossain ${ }^{1, *},\left(\mathbb{D}\right.$, Md. Nazrul Islam $^{6,(\mathbb{D})}$ \\ ${ }^{1}$ Sociology Discipline, Social Science School, Khulna University, Khulna, Bangladesh \\ ${ }^{2}$ School of Humanities and Social Science, Faculty of Education and Arts, University of Newcastle, Callaghan, NSW 2308, Australia \\ ${ }^{3}$ Statistics Discipline, Science, Engineering \& Technology School, Khulna University, Khulna, Bangladesh \\ ${ }^{4}$ Development Studies Discipline, Social Science School, Khulna University, Khulna, Bangladesh \\ ${ }^{5}$ Social and Political Science (SPS) Program, Faculty of Arts, Monash University, Clayton 3168, Melbourne, Australia \\ ${ }^{6}$ Forestry and Wood Technology Discipline, Life Science School, Khulna University, Khulna, Bangladesh
}

\section{ARTICLE INFO}

\section{Article History}

Received 07 October 2020

Accepted 02 January 2021

\section{Keywords}

COVID-19

generalized anxiety

depression

fear

subjective sleep quality

students

Bangladesh

\begin{abstract}
The aim of this study was to determine the risk factors associated with generalized anxiety, depression, and subjective sleep quality among university students during the Coronavirus Disease 2019 (COVID-19) pandemic in Bangladesh. Data for this web-based cross-sectional study were collected from 1317 university students from 49 universities using a self-administered e-questionnaire in the last week of April 2020. Findings suggest that university students have been experiencing heightened generalized anxiety (51\%), depression (45.9\%), and poor subjective sleep quality (27.1\%). Results also indicate that university students were severely frightened about COVID-19. The severity of fear and geographical locations were the key determinants in shaping the state of mind as well as subjective sleep quality of university students. It is, therefore, strongly recommended to initiate not only effective strategies to reduce the transmission of COVID-19 but also a strict monitoring mechanism to detect the presence of mental ailments among university students, and to offer necessary supports through family, community, and institutional agencies to curb psychological problems, especially during this unprecedented health emergency.
\end{abstract}

(C) 2021 Dr. Sulaiman Al Habib Medical Group. Publishing services by Atlantis Press International B.V. This is an open access article distributed under the CC BY-NC 4.0 license (http://creativecommons.org/licenses/by-nc/4.0/).

\section{INTRODUCTION}

In December 2019, the novel Coronavirus Disease 2019 (COVID-19), which originated in Wuhan, the capital of Hubei province, China, spread around the world, forcing the World Health Organization (WHO) to recognize this unanticipated health emergency as a global pandemic on March 11, 2020 [1]. Like the high case-fatality rate of its predecessors, Severe Acute Respiratory Syndrome (SARS) in 2002 and Middle East Respiratory Syndrome (MERS) in 2012 [2], the New Coronavirus, has also become a global challenge in the absence of specific antidotes or vaccines. As of November 17, 2020, more than 53 million people have been infected worldwide, and about 1.3 million individuals have died, mostly in the Americas and Europe [3].

International communities across the globe have been mobilizing different strict antiepidemic preventive measures to contain "human-to-human" transmission in the absence of effective vaccines or antiviral drugs [4,5]. These include shutting down both

"Corresponding author. Email: tanvirku05@soc.ku.ac.bd

Peer review under responsibility of the Dr. Sulaiman Al Habib Medical Group

Data availability statement: The data that support the findings of this study are available from the Harvard Dataverse (https://doi.org/10.7910/DVN/LN7GCJ). administrative and educational institutions, closing the transit system and public spaces, and introducing online/distant learning for students and "work from home" for employees [5-7]. Moreover, governments are also trying to improve public awareness through different strategic interventions, such as providing daily updates on mass media, to encourage people to practice "social distancing" and "home staying" [7-9]. Although some countries relied initially on "herd immunity" [10], later on attention was given to development of effective vaccines for treating infected individuals and people at risk [11]. Some COVID-19 vaccines currently undergoing clinical trials show promising outcomes; however, scientific uncertainties as well as the possible unavailability and unequitable access to low- and middle-income countries continue to revolve around these vaccines $[4,12]$. Thus, experts have been emphasizing the use of nontherapeutic interventions to minimize the spread of COVID-19 [4,5,12]. However, prolonged isolation in the form of quarantine and social distance generates a sense of isolation, stigmatization, and deprivation, and subsequently produces the symptoms of anxiety and depression [13-17], especially among students as they were found to be at higher risk of developing mental health problems during SARS in China [18]. Their increased exposure to mass media [8,9] with daily updates of new infections and fatalities is also amplifying anxiety and fear $[19,20]$. 
Studies found that the combination of anxiety and fear profoundly affects sleep quality [21-24], particularly among the younger population [24-26]. It is important to note that the impact of an outbreak of infectious diseases on mental health problems may exist even after the end of an epidemic, as evidenced from SARS and MERS cases [27,28], and may adversely affect the psychological adjustments of students [18].

Since the beginning of the COVID-19 pandemic, the mental health problems of people, including infected, suspected, and noninfected individuals, has been measured systematically both at individual and social levels in different countries [29-31] to reduce "moral panic" and to devise effective measures for the mental wellbeing of people [6,8,9,32,33], especially students [33-36]. However, people are worried about getting infected if they interact with others, and such discernment-the by-product of an ongoing pandemic-has been increasing anxiety, depression, and stress among people [37]. Studies suggest the presence of heightened fear, anxiety, and stress in the general population during health emergencies $[27,38]$, and these negative emotional and mental health settings adversely affect the sleep quality of the public [21,25], particularly university students [39]. Thus, a systematic and holistic approach to address mental health issues and associated risk factors could be an effective way of implementing targeted interventions to reduce panic among the mass population and to boost resilience [40]. For example, the active psychological interventions in China during the SARS epidemic in 2002 proved to be an effective mechanism to reduce mental stress [41]. Hence, this study was designed to address the mental health issues of university students in the present context of the COVID-19 pandemic. In this background, the main objectives of this paper were to measure the presence of anxiety, depression, and sleep quality among university students in Bangladesh, and to identify their determinants. The outcome is to prescribe coping strategies for policymakers to improve the overall mental health conditions of students, and the general population at large, in Bangladesh.

\section{MATERIALS AND METHODS}

\subsection{Participants and Data Collection Procedures}

Before the countrywide lockdown, all educational institutions in Bangladesh were initially closed from March 18, 2020 until the end of the month, and later extended up to the end of May, 2020 . Hence, this web-based cross-sectional study was carried out in the last week of April 2020, from April 22 until April 30, 2020. Moreover, to comply with the WHO recommendation for "social distancing" (i.e., avoiding face-to-face contact with potential participants), we opted to use e-questionnaire. The target population consisted of university students in Bangladesh, and based on specific criteria, for example, (1) a Bangladeshi and (2) enrolled in a public or private university. A total of 1365 anonymous responses from 49 universities across the country were received. The participants were recruited via an online survey through their Facebook account using the widely used Google form. From the initial batch of responses, 1317 responses were deemed suitable for use in this study after a thorough scrutiny.

\subsection{Ethical Issues}

This study was conducted in accordance with the Declaration of Helsinki, and formal ethical approval was granted from the Ethical Clearance Committee of Khulna University, Khulna, Bangladesh. The participants responded to this online survey by filling up a written informed consent letter in the first section of the e-questionnaire. All participants, responding anonymously to the e-questionnaire, were provided with information concerning the research purpose, confidentiality of information, and right to revoke participation without prior justification in the consent form.

\subsection{Variables}

\subsubsection{Basic characteristics}

A range of factors was included in this study, such as age, sex, enrolled program, place of residence, division (the principal administrative territory in Bangladesh), and the 4-Point Fear of COVID-19 Scale (4P-FCV-19S), based on previous studies [8,29,34]. Furthermore, religion, relationship status, marital status, and type of university were included so we could understand their influence on the extent of anxiety, depression, and sleep quality during the COVID-19 pandemic in Bangladesh.

\subsubsection{Fear}

We used the 4P-FCV-19S, developed from the FCV-19S by Ahorsu et al. [29], to measure fear experienced by university students. The original FCV-19S, a seven-item unidimensional scale, used 5-point Likert-type responses, in which higher scores signified greater fear. In the self-reporting 4P-FCV-19S, we used the seven-item unidimensional construct. However, it was measured on a 4-point Likert-type response, excluding "neither agree nor disagree," and the score ranged from 0 (strongly disagree) to 3 (strongly agree). We conducted a Confirmatory Factor Analysis (CFA). Following a Principal Component Analysis (PCA) by varimax rotation, the preliminary sampling adequacy analysis was satisfactory, with a Kaiser-Meyer-Olkin (KMO) value of 0.890 and Bartlett's test of sphericity was significant as well $\left(\chi_{120}^{2}=3658.112_{21}, p<0.000\right)$. The PCA results suggest a single construct, accounting for $55.45 \%$ of the total variance. Subsequently, a CFA was executed to verify the coherence of the single construct. The seven items were validated by assessing the Construct Reliability (CR) as well as the Average Variance Extracted (AVE). The results, obtained from CFA, were satisfactory: root mean square error of approximation $=0.045<$ 0.060 ; standardized root mean square residual $=0.014<0.080$; and Comparative Fit Index $(\mathrm{CFI})=0.996<0.950[42,43]$. The internal consistency ( $\alpha=0.865)$, CR (0.86), and AVE (0.47) of the unidimensional measurement of 4P-FCV-19S were satisfactory and within the threshold [44-46]. The responses of 4P-FCV-19S were recoded into "not afraid," "moderately afraid," and "severely afraid."

\subsubsection{Generalized anxiety}

Previous COVID-19-related studies have measured the anxiety by different instruments, including Generalized Anxiety 
Disorder Scale-7 (GAD-7) [8,9,34], Coronavirus Anxiety Scale [30], Short Health Anxiety Inventory [31], and Hospital Anxiety and Depression Scale [29]. A few have assessed the variability of different instruments to predict the nature and extent of anxiety $[47,48]$. In this study, however, we measured anxiety using GAD-7 [49]. The self-reporting GAD-7 consisted of seven items assessing the prevalence of anxiety symptoms over the past 2 weeks. On a 4 -point scale, including "not at all" (score $=0$ ), "several days" (score $=1$ ), "more than half of the days" ( score $=2$ ), and "nearly every day" ( of anxiety symptoms was calculated by a total score of 10 or greater, with a higher score indicating the existence of severe anxiety $[9,49]$. The Cronbach $\alpha$ in this study was 0.87 .

\subsubsection{Depression}

We assessed the depression by the WHO Five Well-Being Index (WHO-5) [50]. The self-reporting WHO-5 contained five items, with a 6-point scale ranging from 5 ("all the time") to 0 ("at no time"), reflecting the presence or absence of well-being. The total score ranged from 0 to 25, and a summed score lower than 13 indicates depression among the participants $[8,9,50]$. In this study, the Cronbach $\alpha$ was 0.88 .

\subsubsection{Subjective sleep quality}

The Pittsburgh Sleep Quality Index (PSQI) was developed by Buysse et al. [51]. The self-reporting PSQI, which consists of seven components with a total of 24 questions, assesses the quality of sleep during the previous month. Each element has its own unique score, ranging from 0 to 3 , with higher points signifying poor subjective sleep quality. In this study, we used only the first component of PSQI- "subjective sleep quality" — on a 4-point scale: "very good," "fairly good," "fairly bad," and "very bad," scored as 0, 1, 2, and 3. The responses were recoded into "good" ("very good" and "fairly good") and "bad" ("fairly bad" and "very bad").

\subsection{Statistical Analysis}

Data were analyzed in three consecutive stages (see Data Repository) using SPSS version 20 (SPSS Inc., Chicago, IL, USA) and AMOS version 23 (IBM, Armonk, NY, USA). First, CFA was performed to validate the 4P-FCV-19S. Second, Pearson's Chi-square $\left(\chi^{2}\right)$ test of independence was performed in bivariate analysis to measure the association of explanatory variables with anxiety, depression, and sleep quality at a $5 \%$ level of significance. Finally, the multivariable logistic regression model was performed considering the variables found statistically significant in Pearson's $\chi^{2}$ test. Findings were shown using the Adjusted Odds Ratio (AOR) with 95\% confidence intervals (95\% CI).

\section{RESULTS}

\subsection{Basic Characteristics}

Table 1 illustrates the characteristics of participants. Among the participants, $61.2 \%$ were from the age group of $21-24$ years, and the average age was 22.1 (standard deviation, \pm 2.2 ) years. Nearly $60 \%$ of the participants were male, and nine out of 10 students were Muslims (86.7\%) and not engaged in any relationship (84.5\%). Less than $10 \%$ of all participants were married. Two-thirds of the students lived in urban areas (64.1\%), and about half of them (46.4\%) were from the Khulna division. Among the participants, $64.1 \%$ were enrolled in undergraduate programs, mostly in public universities (87.5\%). Three out of five students were experiencing FCV-19 in Bangladesh.

\subsection{Prevalence of Anxiety, Depression, and Sleep Quality among University Students}

Table 1 also shows the prevalence of anxiety, depression, and subjective sleep quality among university students in Bangladesh. The overall prevalence of anxiety, depression, and poor subjective sleep quality was $51 \%, 45.9 \%$, and $27.1 \%$, respectively. In case of anxiety, the prevalence of anxiety was almost the same among various age groups and religious sects. By contrast, anxiety was higher among females (54.4\%) and "single" (52.4\%) students than among those who are involved in any type of relationship. Likewise, anxiety was highly prevalent among students from the Khulna division (56.1\%), and those who were severely frightened of COVID-19 (80.5\%). For depression, students in the 21-24 (48.5\%) years age group were more depressed than their older and younger counterparts. Female students suffered from greater depression (51.5\%) than males. Interestingly, students from public universities showed a higher rate of depressive symptoms (47.3\%) than those who attended private universities. Moreover, FCV-19 played a critical role as the severity of depression was higher among students with greater fear of the pandemic (56.4\%). In case of sleep quality, apparently older (32\%) and female $(31.6 \%)$ students experienced poor subjective sleep quality during the COVID-19 pandemic than their younger and male counterparts, respectively. Likewise, subjective sleep quality tends to be poorer for urban students (29.9\%) and students enrolled in graduate and postgraduate programs (28\%). Like anxiety and depression, poor subjective sleep quality was more prevalent among students who were severely terrified of the COVID-19 pandemic (43\%) than those who felt moderate or no fear.

In addition, Table 1 also shows the association of anxiety, depression, and sleep quality with various explanatory factors. Findings indicate that $\operatorname{sex}(p=0.035)$, relationship status $(p=0.021)$, division $(p=0.004)$, and 4P-FCV-19S $(p<0.001)$ were significantly associated with anxiety. Meanwhile, age $(p<0.001)$, sex $(p=0.033)$, type of university $(p=0.005)$, and 4P-FCV-19S $(p<0.001)$ had a statistically significant influence on the prevalence of depression among university students. Finally, results suggest that age $(p=0.050)$, sex $(p=0.002)$, place of residence $(p=0.003)$, enrolled program $(p=0.004)$, and 4P-FCV-19S $(p<0.001)$ significantly explained the sleep quality of students.

\subsection{Multivariate Analysis}

From the bivariate analysis, the significant factors of at least one case of anxiety or depression or poor subjective sleep quality were considered to present unadjusted effects of different independent variables. In multivariate analysis, the binary logistic regression models were carried out to identify the adjusted effect of the 
Table 1 Prevalence of anxiety, depression and sleep quality among university students

\begin{tabular}{|c|c|c|c|c|c|c|c|c|c|c|c|}
\hline \multirow{2}{*}{ Variables } & \multirow{2}{*}{$n$} & \multirow{2}{*}{$\%$} & \multicolumn{3}{|c|}{ Anxiety } & \multicolumn{3}{|c|}{ Depression } & \multicolumn{3}{|c|}{ Sleep quality } \\
\hline & & & $n$ & $\%$ & $p$ & $n$ & $\%$ & $p$ & $n$ & $\%$ & $p$ \\
\hline Overall & 1317 & 100 & 672 & 51.0 & & 604 & 45.9 & & 357 & 27.1 & \\
\hline \multicolumn{12}{|l|}{ Age (in years) } \\
\hline$\leq 20$ & 333 & 25.3 & 171 & 51.4 & \multirow{3}{*}{0.955} & 144 & 43.2 & \multirow{3}{*}{$<0.001$} & 75 & 22.5 & \multirow{3}{*}{0.050} \\
\hline $21-24$ & 806 & 61.2 & 412 & 51.1 & & 391 & 48.5 & & 225 & 27.9 & \\
\hline$\geq 25$ & 178 & 13.5 & 89 & 50.0 & & 69 & 38.8 & & 57 & 32.0 & \\
\hline \multicolumn{12}{|l|}{ Sex } \\
\hline Male & 766 & 58.2 & 372 & 48.6 & \multirow{2}{*}{0.035} & 320 & 41.8 & \multirow{2}{*}{0.033} & 183 & 23.9 & \multirow{2}{*}{0.002} \\
\hline Female & 551 & 41.8 & 300 & 54.4 & & 284 & 51.5 & & 174 & 31.6 & \\
\hline \multicolumn{12}{|l|}{ Religious identity } \\
\hline Muslim & 1142 & 86.7 & 581 & 50.9 & \multirow{2}{*}{0.782} & 515 & 45.1 & \multirow{2}{*}{0.154} & 312 & 27.3 & \multirow{2}{*}{0.656} \\
\hline Others & 175 & 13.3 & 91 & 52.0 & & 89 & 50.9 & & 45 & 25.7 & \\
\hline \multicolumn{12}{|l|}{ Relationship status } \\
\hline Single & 1113 & 84.5 & 583 & 52.4 & \multirow{2}{*}{0.021} & 506 & 45.5 & \multirow{2}{*}{0.497} & 294 & 26.4 & \multirow{2}{*}{0.187} \\
\hline In a relationship & 204 & 15.5 & 89 & 43.6 & & 98 & 48.0 & & 53 & 26.0 & \\
\hline \multicolumn{12}{|l|}{ Marital status } \\
\hline Unmarried & 1243 & 94.4 & 640 & 51.5 & 0168 & 573 & 46.1 & 0481 & 332 & 26.7 & 0184 \\
\hline Married & 74 & 5.6 & 32 & 43.2 & 0.108 & 31 & 41.9 & 0.481 & 25 & 33.8 & 0.184 \\
\hline Place of residence & & & & & & & & & & & \\
\hline Rural & 473 & 35.9 & 248 & 52.4 & & 201 & 42.5 & & 105 & 22.2 & \\
\hline Urban & 844 & 64.1 & 424 & 50.2 & 0.445 & 403 & 47.7 & 0.066 & 252 & 29.9 & 0.003 \\
\hline Division & & & & & & & & & & & \\
\hline Barishal & 28 & 2.1 & 11 & 39.3 & & 14 & 50.0 & & 8 & 28.6 & \\
\hline Chattogram & 169 & 12.8 & 71 & 42.0 & & 82 & 48.5 & & 42 & 24.9 & \\
\hline Dhaka & 247 & 18.8 & 121 & 49.0 & & 112 & 45.3 & & 74 & 30.0 & \\
\hline Khulna & 611 & 46.4 & 343 & 56.1 & & 281 & 46.0 & & 183 & 30.0 & \\
\hline Mymensingh & 64 & 4.9 & 35 & 54.7 & 0.004 & 23 & 35.9 & 0.793 & 11 & 17.2 & 0.058 \\
\hline Rajshahi & 117 & 8.9 & 59 & 50.4 & & 57 & 48.7 & & 26 & 22.2 & \\
\hline Rangpur & 70 & 5.3 & 30 & 42.9 & & 30 & 42.9 & & 11 & 15.7 & \\
\hline Sylhet & 11 & 0.8 & 2 & 18.2 & & 5 & 45.5 & & 2 & 18.2 & \\
\hline Enrolled program & & & & & & & & & & & \\
\hline Undergraduate & 846 & 64.2 & 431 & 50.9 & & 398 & 47.0 & & 225 & 26.6 & \\
\hline Graduate and postgraduate & 471 & 35.8 & 241 & 51.2 & 0.938 & 206 & 43.7 & $0.15 /$ & 132 & 28.0 & 0.004 \\
\hline Type of university & & & & & & & & & & & \\
\hline Public & 1152 & 87.5 & 587 & 51.0 & 0893 & 545 & 47.3 & 0005 & 304 & 26.4 & 0121 \\
\hline Private & 165 & 12.5 & 85 & 51.5 & 0.893 & 59 & 35.8 & 0.005 & 53 & 32.1 & 0.121 \\
\hline 4P-FCV-19S & & & & & & & & & & & \\
\hline Not afraid & 184 & 14.0 & 43 & 23.4 & & 54 & 29.3 & & 33 & 17.9 & \\
\hline Moderately afraid & 784 & 59.5 & 348 & 44.4 & $<0.001$ & 353 & 45.0 & $<0.001$ & 174 & 22.2 & $<0.001$ \\
\hline Severely afraid & 349 & 26.5 & 281 & 80.5 & & 197 & 56.4 & & 150 & 43.0 & \\
\hline
\end{tabular}

explanatory variables. The odds ratio measured the adjusted effect of the independent variables along with a 95\% CI after controlling for the effects of all other explanatory variables.

\subsubsection{Determinants of anxiety}

Table 2 presents the findings of the multivariate analysis of anxiety. The results showed that several factors, such as relationship status, division, and FCV-19, were the most significant determinants of anxiety among university students in Bangladesh. Results revealed that students involved in a relationship had higher adjusted odds of anxiety $(\mathrm{AOR}=0.68 ; 95 \% \mathrm{CI}, 0.49-0.96 ; p=0.026)$ than those with "single" relationship status. Among seven administrative divisions, students from Chattogram, Dhaka, Khulna, Rajshahi, Rangpur, and Sylhet had 0.32 (95\% CI, 0.19-0.52; $p<0.001$ ), 0.47 (95\% CI,
$0.30-0.74 ; p=0.001), 0.50$ (95\% CI, $0.34-0.75 ; p=0.001), 0.46(95 \%$ CI, $0.27-0.78 ; p=0.004), 0.32$ (95\% CI, $0.17-0.60 ; p<0.001)$, and 0.15 (95\% CI, $0.03-0.75 ; p=0.021)$ times lower odds of anxiety than those from Barishal. Furthermore, students who were moderately and severely afraid of COVID-19 were 2.06 (95\% CI, 1.47-2.88; $p<$ $0.001)$ and 10.39 (95\% CI, 6.88-15.68; $p<0.001)$ times more likely to develop anxiety, respectively, than those who were not afraid at all.

\subsubsection{Determinants of depression}

Table 2 demonstrates the level depression among university students of Bangladesh. The results reveal that division, type of university, and FCV-19 have a significant impact on depression. Students from private universities were 0.58 times (95\% CI, $0.40-0.83$; $p=$ 0.003 ) less likely to be depressed than those enrolled in public 
Table 2 Binary logistic regression analysis of anxiety, depression, and sleep quality and their predictors

\begin{tabular}{|c|c|c|c|c|c|c|c|c|c|c|c|c|}
\hline \multirow{3}{*}{ Variables } & \multicolumn{4}{|c|}{ Anxiety } & \multicolumn{4}{|c|}{ Depression } & \multicolumn{4}{|c|}{ Poor subjective sleep quality } \\
\hline & \multirow{2}{*}{ AOR } & \multicolumn{2}{|c|}{ 95\% CI for AOR } & \multirow{2}{*}{$p$} & \multirow{2}{*}{ AOR } & \multicolumn{2}{|c|}{ 95\% CI for AOR } & \multirow{2}{*}{$p$} & \multirow{2}{*}{ AOR } & \multicolumn{2}{|c|}{ 95\% CI for AOR } & \multirow{2}{*}{$p$} \\
\hline & & Lower & Upper & & & Lower & Upper & & & Lower & Upper & \\
\hline $\begin{array}{l}\text { Age (years) } \\
\leq 20\end{array}$ & & & & & & & & & & & & \\
\hline $\begin{array}{l}21-24 \\
\geq 25\end{array}$ & $\begin{array}{l}0.93 \\
1.00\end{array}$ & $\begin{array}{l}0.71 \\
0.64\end{array}$ & $\begin{array}{l}1.23 \\
1.57\end{array}$ & $\begin{array}{l}0.617 \\
0.991\end{array}$ & $\begin{array}{l}1.22 \\
0.91\end{array}$ & $\begin{array}{l}0.94 \\
0.59\end{array}$ & $\begin{array}{l}1.60 \\
1.39\end{array}$ & $\begin{array}{l}0.137 \\
0.654\end{array}$ & $\begin{array}{l}1.18 \\
1.60\end{array}$ & $\begin{array}{l}0.87 \\
1.01\end{array}$ & $\begin{array}{l}1.60 \\
2.56\end{array}$ & $\begin{array}{l}0.291 \\
0.049\end{array}$ \\
\hline $\begin{array}{l}\text { Sex } \\
\text { Male } \\
\text { Female }\end{array}$ & 0.99 & 0.77 & 1.28 & 0.949 & 1.23 & 0.97 & 1.55 & 0.095 & 1.22 & 0.93 & 1.59 & 0.149 \\
\hline $\begin{array}{l}\text { Relationship status } \\
\text { Single } \\
\text { In a relationship }\end{array}$ & 0.68 & 0.49 & 0.96 & 0.026 & 1.09 & 0.80 & 1.50 & 0.584 & 1.07 & 0.76 & 1.52 & 0.703 \\
\hline $\begin{array}{l}\text { Place of residence } \\
\text { Rural } \\
\text { Urban }\end{array}$ & 0.95 & 0.74 & 1.22 & 0.667 & 1.23 & 0.97 & 1.56 & 0.092 & 1.27 & 0.97 & 1.67 & 0.088 \\
\hline $\begin{array}{l}\text { Division } \\
\text { Barishal }\end{array}$ & & & & & & & & & & & & \\
\hline $\begin{array}{l}\text { Chattogram } \\
\text { Dhaka } \\
\text { Khulna } \\
\text { Mymensingh } \\
\text { Rajshahi } \\
\text { Rangpur } \\
\text { Sylhet }\end{array}$ & $\begin{array}{l}0.32 \\
0.47 \\
0.50 \\
0.55 \\
0.46 \\
0.32 \\
0.15\end{array}$ & $\begin{array}{l}0.19 \\
0.30 \\
0.34 \\
0.29 \\
0.27 \\
0.17 \\
0.03\end{array}$ & $\begin{array}{l}0.52 \\
0.74 \\
0.75 \\
1.02 \\
0.78 \\
0.60 \\
0.75\end{array}$ & $\begin{array}{r}<0.001 \\
0.001 \\
0.001 \\
0.058 \\
0.004 \\
<0.001 \\
0.021\end{array}$ & $\begin{array}{l}0.41 \\
0.38 \\
0.39 \\
0.27 \\
0.43 \\
0.36 \\
0.42\end{array}$ & $\begin{array}{l}0.26 \\
0.24 \\
0.26 \\
0.14 \\
0.26 \\
0.20 \\
0.12\end{array}$ & $\begin{array}{l}0.66 \\
0.59 \\
0.57 \\
0.49 \\
0.71 \\
0.65 \\
1.48\end{array}$ & $\begin{array}{r}<0.001 \\
<0.001 \\
<0.001 \\
<0.001 \\
0.001 \\
0.001 \\
0.179\end{array}$ & $\begin{array}{l}0.19 \\
0.23 \\
0.21 \\
0.12 \\
0.18 \\
0.11 \\
0.17\end{array}$ & $\begin{array}{l}0.11 \\
0.14 \\
0.14 \\
0.06 \\
0.10 \\
0.05 \\
0.04\end{array}$ & $\begin{array}{l}0.33 \\
0.37 \\
0.32 \\
0.26 \\
0.32 \\
0.23 \\
0.84\end{array}$ & $\begin{array}{c}<0.001 \\
<0.001 \\
<0.001 \\
<0.001 \\
<0.001 \\
<0.001 \\
0.03\end{array}$ \\
\hline $\begin{array}{l}\text { Enrolled program } \\
\text { Undergraduate } \\
\text { Graduate and } \\
\text { post-graduate }\end{array}$ & 0.99 & 0.76 & 1.30 & 0.964 & 0.86 & 0.66 & 1.11 & 0.246 & 0.91 & 0.68 & 1.22 & 0.538 \\
\hline $\begin{array}{l}\text { Type of university } \\
\text { Public } \\
\text { Private }\end{array}$ & 0.90 & 0.62 & 1.30 & 0.561 & 0.58 & 0.40 & 0.83 & 0.003 & 1.17 & 0.80 & 1.72 & 0.41 \\
\hline $\begin{array}{l}\text { 4P-FCV-19S } \\
\text { Not afraid } \\
\text { Moderately afraid } \\
\text { Severely afraid }\end{array}$ & $\begin{array}{r}2.06 \\
10.39\end{array}$ & $\begin{array}{l}1.47 \\
6.88\end{array}$ & $\begin{array}{r}2.88 \\
15.68\end{array}$ & $\begin{array}{l}<0.001 \\
<0.001\end{array}$ & $\begin{array}{l}1.67 \\
2.66\end{array}$ & $\begin{array}{l}1.20 \\
1.84\end{array}$ & $\begin{array}{l}2.32 \\
3.85\end{array}$ & $\begin{array}{r}0.002 \\
<0.001\end{array}$ & $\begin{array}{l}0.92 \\
2.45\end{array}$ & $\begin{array}{l}0.64 \\
1.65\end{array}$ & $\begin{array}{l}1.32 \\
3.64\end{array}$ & $\begin{array}{c}0.64 \\
<0.001\end{array}$ \\
\hline
\end{tabular}

universities. Among the seven administrative divisions, the odds of depression in students who hail from Chattogram, Dhaka, Khulna, Mymensingh, Rajshahi, and Rangpur were 0.41 (95\% CI, 0.26-0.66; $p<0.001$ ), 0.38 (95\% CI, 0.34-0.59; $p<0.001$ ), 0.39 (95\% CI, 0.26$0.57 ; p<0.001$ ), 0.27 (95\% CI, $0.14-0.49 ; p<0.001$ ), 0.43 (95\% CI, $0.26-0.71 ; p=0.001)$, and $0.36(95 \% \mathrm{CI}, 0.20-0.65 ; p=0.001)$ times lower than those from Barishal division. Meanwhile, students who were moderately and severely afraid of COVID-19 were 1.67 (95\% CI, $1.20-2.32 ; p=0.002)$ and 2.66 (95\% CI, 1.84-3.85; $p<0.001)$ times more likely to experience depression, respectively, than those who were not afraid.

\subsubsection{Determinants of poor subjective sleep quality}

Table 2 presents the determinants of poor subjective sleep quality among Bangladeshi students. Various factors, such as age, division, and FCV-19, had a significant impact on poor subjective sleep quality. Older students ( $\geq 25$ years old) were 1.60 times $(95 \% \mathrm{CI}$, $1.01-2.54 ; p=0.049)$ more likely to experience poor subjective sleep quality than those from the younger age cohort. Students who lived in Chattogram, Dhaka, Khulna, Mymensingh, Rajshahi, Rangpur, and Sylhet had 0.19 (95\% CI, 0.11-0.33; $p<0.001), 0.23$ (95\% CI, 0.14-0.37; $p<0.001$ ), 0.21 (95\% CI, 0.14-0.32; $p<0.001$ ), 0.12 (95\% CI, 0.06-0.26; $p<0.001$ ), 0.18 (95\% CI, 0.10-0.32; $p<$ 0.001 ), 0.11 (95\% CI, 0.05-0.23; $p<0.001$ ), and 0.17 (95\% CI, $0.04-$ $0.84 ; p=0.030)$ times lower odds of poor subjective sleep quality compared with the students from Barishal division. The odds of poor subjective sleep quality among severely afraid students were 2.45 times (95\% CI, 1.65-3.64; $p<0.001$ ) higher compared with those who were not afraid of the COVID-19 pandemic.

\section{DISCUSSION}

This study aimed to identify the prevalence of anxiety, depression, and subjective sleep quality among university students in Bangladesh and determine the factors contributing to the presence of anxiety and depression symptoms and changes in sleep quality during the COVID-19 pandemic. Findings reveal that symptoms of anxiety (51\%) and depression (45.9\%) were on the rise among 
university students, whereas sleep quality has been decreasing as more than $27.1 \%$ of students were experiencing poor subjective sleep quality. The nationwide survey on mental health in Bangladesh suggests that the prevalence of anxiety, depression, and poor subjective sleep quality was $6.7 \%, 4.5 \%$, and $0.9 \%$, respectively [52]. The extraordinary increase of anxiety, depression, and poor subjective sleep quality during health emergencies is not uncommon. Previous studies often reported heightened mental health problems among people of different cohorts during and after epidemics [53-57] and the recent pandemic around the world [9,29-31,33,34,58].

Further findings indicate that symptoms of anxiety and depression, along with poor subjective sleep quality, were strongly related to division-the principal administrative regions in Bangladesh. Students from all administrative divisions, with some exceptions, showed symptoms of anxiety, depression, and poor subjective sleep quality. In a similar vein, Yang et al. [35], in a study conducted on Chinese university students, observed that students from all provinces in China, irrespective of "severity of the risk," showed similar symptoms of anxiety and fear as a result of "mass hysteria" [59]. Other studies associated heightened mental health problems with proximity of an epicenter of an outbreak [6,8,34,60]. There is no denying that health systems around the world are getting overwhelmed with increased demands for necessary health assistance, especially for COVID-19 patients. Hence, limited health facilities, together with unmet needs, especially for people at higher risk, propel widespread panic among general populations. In Bangladesh, the government implemented a countrywide lockdown and adopted a public campaign of social distancing as well as respiratory and hand hygiene. Nevertheless, the limited number of healthcare facilities designated for treatment of infected patients together with the insufficient number of testing centers, and shortage of test kits and Personal Protective Equipment (PPE) for frontline personnel (e.g., like healthcare professionals) are contributing to the surge of infections in Bangladesh [61], and to greater panic in the general population, particularly among university students. Studies have indicated that students often experience serious mental health problems during public health emergencies $[34,36,62,63]$.

Another factor adversely affecting anxiety, depression, and sleep quality of university students in Bangladesh was fear, measured by 4P-FCV-19S. Previous studies addressing the psychological impact of the large-scale epidemic suggest that people, both infected and noninfected, who are suffering from fear of diseases are highly susceptible to prolonged mental health problems [18,57]. The "infodemic" overload through mass media is also influencing the nature and magnitude of mental health issues, including fear, during epidemics and pandemics $[8,9,64]$. As in many other countries, the people of Bangladesh were well informed about the outbreak of COVID-19 and the declaration of the pandemic through mainstream mass media. Studies suggest that exposure to mass media during medical health emergencies may have a positive influence on forming risk perceptions [65]. However, overwhelming negative information during lockdown also amplifies mass panic among people regarding the disease itself and generates stigmatization as well as discrimination against the infected, the suspected, and the people at risk of infection because of the intense uncertainty [14,66-69]. Stigmatization during and after the crisis may lead to suicidal behavior in certain individuals, as studies reported increased suicide rate during various health emergencies, such as the great influenza epidemic of 2018 [57], SARS epidemic in 2003 [70], and even the current pandemic [66-69].
Findings of this study show that university type has a significant influence on the presence of depression among university students in Bangladesh during the COVID-19 pandemic. Students from public universities were more susceptible to depression than their counterparts in private universities during the pandemic. Previous studies tracing depression among university students in Bangladesh suggest that the likelihood of depression is higher among students from lower socioeconomic background than students from higher socioeconomic families [71] largely because of strained financial conditions as well as uncertainty over their future career [72]. Needless to say, private universities in Bangladesh are "profit-making" institutions that commercialized education by fixing unrestrained, high tuition fees $[73,74]$, thus making it difficult for middle- or lower-income families to send their children to private universities. During the pandemic, their struggle has worsened even further as preventive interventions, such as lockdown and home quarantine, have disrupted the financial and production activities of small and medium business enterprises [75], compelling family members to get engaged in odd jobs, intensifying mental health problems [76] and sometimes leading to selfdestructive activities such as self-harm and suicide $[66,69]$.

The validity of these observations is subjected to various issues. For example, data were collected quickly within a week. However, the participants' further experiences over the coming weeks would bring greater clarity about the phenomenon reported here. Selfrating scales were used for assessing generalized anxiety, depression, subjective sleep quality, as well as fear. Hence, the risk of false judgment and biases of social desirability cannot be denied. This study, which is cross-sectional in nature, might not accurately explain the causal relation between anxiety, depression, and subjective sleep quality with explanatory factors. Furthermore, data were collected from a small population sample using Facebook, covering only university students, and may not be generalized to other settings and populations. A nationwide, large-scale study would present different experiences and issues. Therefore, systematic longer follow-up studies are recommended to determine the impact of COVID-19 on the mental health of the public, including the younger population in Bangladesh.

\section{CONCLUSION}

Like many other developing countries, Bangladesh focused mainly on controlling COVID-19 transmission at community levels and providing treatment to infected as well as suspected patients. However, the findings of the current study show that the young population is experiencing adverse and heightened mental health problems, regardless of geographical variations, with possible prolonged mental health outcomes if the problem is not adequately addressed. Furthermore, FCV-19 among university students is also growing at an unprecedented rate, a result of overexposure to unreliable and unconfirmed information in media outlets. Considering the current situation, the government of Bangladesh needs to implement its "safety" and "survival" strategies in different phases. First, policymakers, guided by expert opinion, should launch a nationwide epidemiological study addressing the nature and magnitude of mental health problems, including anxiety, depression, fear as well as stress, and relevant issues with emphasis on young adults. Based on the outcomes, they should implement age-specific emergency psychological interventions and supports-for infected, 
suspected, and noninfected individuals. Second, the University Grants Commission of Bangladesh, together with government health authorities, should provide necessary information by setting up a support network using available online platforms to assist students, faculties, and other professionals involved in higher academia to fight against mental ailments during the ongoing health emergency. Finally, lawmakers should initiate an active surveillance and monitoring system to reduce "misinformation" and "infodemic" to help curb mass panic in Bangladesh.

\section{CONFLICTS OF INTEREST}

The authors declare they have no conflicts of interest.

\section{AUTHORS' CONTRIBUTION}

T-E-AS acquisition of data, preparing the first draft, giving approval for the final version to be published. BA data analysis/interpretation, preparing the first draft, giving approval for the final version to be published. BK acquisition of data, giving approval for the final version to be published. NJ acquisition of data, preparing the first draft, critically reviewing the paper, giving approval for the final version to be published. TAS critical review of the paper, giving approval for the final version to be published. MTH principal investigator and corresponding author, conception/design of the protocol, data analysis/interpretation, preparing the first draft, critically reviewing the paper, giving approval for the final version to be published. MNI study supervision, critical review of the paper, giving approval for the final version to be published.

\section{FUNDING}

This research did not receive any specific grant from funding agencies in the public, commercial, or not-for-profit sectors.

\section{ACKNOWLEDGMENTS}

We are thankful to all the participants and the anonymous reviewers.

\section{REFERENCES}

[1] World Health Organization. WHO Director-General's opening remarks at the media briefing on COVID-19 - 11 March 2020. Secondary WHO Director-General's opening remarks at the media briefing on COVID-19 - 11 March 2020. Available from: https://www.who.int/dg/speeches/detail/who-director-generals-opening-remarks-at-the-media-briefing-on-covid-19---11march-2020 (accessed January 7, 2021).

[2] Deng SQ, Peng HJ. Characteristics of and public health responses to the coronavirus disease 2019 outbreak in China. J Clin Med 2020;9;575.

[3] World Health Organization. COVID-19 weekly epidemiological update. Geneva, Switzerland: World Health Organization (WHO); 2020.
[4] Anderson RM, Vegvari C, Truscott J, Collyer BS. Challenges in creating herd immunity to SARS-CoV-2 infection by mass vaccination. Lancet 2020;396;1614-16.

[5] Anwar S, Nasrullah M, Hosen MJ. COVID-19 and Bangladesh: challenges and how to address them. Front Public Health $2020 ; 8 ; 154$

[6] Ahmed MZ, Ahmed O, Aibao Z, Hanbin S, Siyu L, Ahmad A. Epidemic of COVID-19 in China and associated psychological problems. Asian J Psychiatry 2020;51;102092.

[7] Chen L, Yuan X. China's ongoing battle against the coronavirus: why did the lockdown strategy work well? Socio-Ecol Pract Res 2020;2;175-80.

[8] Gao J, Zheng P, Jia Y, Chen H, Mao Y, Chen S, et al. Mental health problems and social media exposure during COVID-19 outbreak. PLoS One 2020;15;e0231924.

[9] Hossain MT, Ahammed B, Chanda SK, Jahan N, Ela MZ, Islam MN. Social and electronic media exposure and generalized anxiety disorder among people during COVID-19 outbreak in Bangladesh: a preliminary observation. PLoS One 2020;15;e0238974.

[10] Omer SB, Yildirim I, Forman HP. Herd immunity and implications for SARS-CoV-2 control. JAMA 2020;324;2095-6.

[11] Dong L, Hu S, Gao J. Discovering drugs to treat coronavirus disease 2019 (COVID-19). Drug Discov Ther 2020;14;58-60.

[12] The Lancet. COVID-19 vaccines: no time for complacency. Lancet 2020;396;1607.

[13] Rehman U, Shahnawaz MG, Khan NH, Kharshiing KD, Khursheed M, Gupta K, et al. Depression, anxiety and stress among Indians in times of Covid-19 lockdown. Community Ment Health J 2021;57;42-8.

[14] Cava MA, Fay KE, Beanlands HJ, McCay EA, Wignall R. The experience of quarantine for individuals affected by SARS in Toronto. Public Health Nurs 2005;22;398-406.

[15] Hawryluck L, Gold WL, Robinson S, Pogorski S, Galea S, Styra R. SARS control and psychological effects of quarantine, Toronto, Canada. Emerg Infect Dis 2004;10;1206-12.

[16] Xiang YT, Yang Y, Li W, Zhang L, Zhang Q, Cheung T, et al. Timely mental health care for the 2019 novel coronavirus outbreak is urgently needed. Lancet Psychiatry 2020;7;228-9.

[17] Zhang J, Wu W, Zhao X, Zhang W. Recommended psychological crisis intervention response to the 2019 novel coronavirus pneumonia outbreak in China: a model of West China Hospital. Precis Clin Med 2020;3;3-8.

[18] Main A, Zhou Q, Ma Y, Luecken LJ, Liu X. Relations of SARSrelated stressors and coping to Chinese college students' psychological adjustment during the 2003 Beijing SARS epidemic. J Couns Psychol 2011;58;410-23.

[19] Walsh JP. Social media and moral panics: assessing the effects of technological change on societal reaction. Int J Cult Stud 2020;23;840-59.

[20] Zheng Y, Goh E, Wen J. The effects of misleading media reports about COVID-19 on Chinese tourists' mental health: a perspective article. Anatolia 2020;31;337-40.

[21] Xiao H, Zhang Y, Kong D, Li S, Yang N. Social capital and sleep quality in individuals who self-isolated for 14 days during the coronavirus disease 2019 (COVID-19) outbreak in January 2020 in China. Med Sci Monit 2020;26;e923921.

[22] Yang Y, Li W, Zhang Q, Zhang L, Cheung T, Xiang YT. Mental health services for older adults in China during the COVID-19 outbreak. Lancet Psychiatry 2020;7;e19. 
[23] Huang Y, Zhao N. Generalized anxiety disorder, depressive symptoms and sleep quality during COVID-19 outbreak in China: a web-based cross-sectional survey. Psychiatry Res 2020;288;112954.

[24] Cellini N, Canale N, Mioni G, Costa S. Changes in sleep pattern, sense of time and digital media use during COVID-19 lockdown in Italy. J Sleep Res 2020;29;e13074.

[25] Shen L, van Schie J, Ditchburn G, Brook L, Bei B. Positive and negative emotions: differential associations with sleep duration and quality in adolescents. J Youth Adolesc 2018;47;2584-95.

[26] Gualano MR, Lo Moro G, Voglino G, Bert F, Siliquini R. Effects of Covid-19 lockdown on mental health and sleep disturbances in Italy. Int J Environ Res Public Health 2020;17;4779.

[27] Lee AM, Wong JGWS, McAlonan GM, Cheung V, Cheung C, Sham PC, et al. Stress and psychological distress among SARS survivors 1 year after the outbreak. Can J Psychiatry 2007;52; 233-40.

[28] Lee SH, Shin HS, Park HY, Kim JL, Lee JJ, Lee H, et al. Depression as a mediator of chronic fatigue and post-traumatic stress symptoms in Middle East respiratory syndrome survivors. Psychiatry Investig 2019;16;59-64.

[29] Ahorsu DK, Lin CY, Imani V, Saffari M, Griffiths MD, Pakpour AH. The fear of COVID-19 scale: development and initial validation. Int J Ment Health Addict 2020;1-9.

[30] Lee SA. Coronavirus Anxiety Scale: a brief mental health screener for COVID-19 related anxiety. Death Stud 2020;44;393-401.

[31] Taylor S, Landry CA, Paluszek MM, Fergus TA, McKay D, Asmundson GJG. Development and initial validation of the COVID Stress Scales. J Anxiety Disord 2020;72;102232.

[32] Chaturvedi SK. Covid-19, coronavirus and mental health rehabilitation at times of crisis. J Psychosoc Rehabil Mental Health 2020;7;1-2.

[33] Islam MA, Barna SD, Raihan H, Khan MNA, Hossain MT. Depression and anxiety among university students during the COVID-19 pandemic in Bangladesh: a web-based cross-sectional survey. PLoS One 2020;15;e0238162.

[34] Cao W, Fang Z, Hou G, Han M, Xu X, Dong J, et al. The psychological impact of the COVID-19 epidemic on college students in China. Psychiatry Res 2020;287;112934.

[35] Yang H, Bin P, He AJ. Opinions from the epicenter: an online survey of university students in Wuhan amidst the COVID-19 outbreak. J Chin Gov 2020;5;234-58.

[36] Zhai Y, Du X. Mental health care for international Chinese students affected by the COVID-19 outbreak. Lancet Psychiatry 2020;7;e22.

[37] Lin CY. Social reaction toward the 2019 novel coronavirus (COVID-19). Soc Health Behav 2020;3;1-2. Available from: https://www.shbonweb.com/text.asp?2020/3/1/1/280554

[38] Wu KK, Chan SK, Ma TM. Posttraumatic stress, anxiety, and depression in survivors of severe acute respiratory syndrome (SARS). J Trauma Stress 2005;18;39-42.

[39] Becker SP, Gregory AM. Editorial perspective: perils and promise for child and adolescent sleep and associated psychopathology during the COVID-19 pandemic. J Child Psychol Psychiatry 2020;61;757-9.

[40] Gualano MR, Lo Moro G, Voglino G, Bert F, Siliquini R. Monitoring the impact of COVID-19 pandemic on mental health: a public health challenge? Reflection on Italian data. Soc Psychiatry Psychiatr Epidemiol 2020;1-3.
[41] Duan L, Zhu G. Psychological interventions for people affected by the COVID-19 epidemic. Lancet Psychiatry 2020;7;300-2.

[42] Brown TA. Confirmatory factor analysis for applied research. 2nd ed. New York: Guilford Press; 2015.

[43] DiLalla LF. Structural equation modeling: uses and issues. In: Tinsley HEA, Brown SD, editors. Handbook of Applied Multivariate Statistics and Mathematical Modeling. San Diego, CA: Academic Press; 2000, pp. 439-64.

[44] Pham TN, Bui LTP. An exploration of students' voices on the English graduation benchmark policy across Northern, Central and Southern Vietnam. Lang Test Asia 2019;9;15.

[45] Hair Jr JF, Black WC, Babin BJ, Anderson RE. Multivariate data analysis. 7th ed. Harlow, Essex: Pearson Publishing Company; 2014.

[46] DeVellis RF. Scale development: theory and application. 2nd ed. Thousand Oaks, CA: Sage Publications Inc.; 2003.

[47] McKay D, Yang H, Elhai J, Asmundson GJG. Anxiety regarding contracting COVID-19 related to interoceptive anxiety sensations: the moderating role of disgust propensity and sensitivity. J Anxiety Disord 2020;73;102233.

[48] Yuan R, Xu QH, Xia CC, Lou CY, Xie Z, Ge QM, et al. Psychological status of parents of hospitalized children during the COVID-19 epidemic in China. Psychiatry Res 2020;288;112953.

[49] Spitzer RL, Kroenke K, Williams JBW, Löwe B. A brief measure for assessing generalized anxiety disorder: the GAD-7. Arch Intern Med 2006;166;1092-7.

[50] Mental Health Centre North Zealand. WHO-5 Questionnaires. Secondary WHO-5 Questionnaires. 2020. Available from: https:// www.psykiatri-regionh.dk/who-5/who-5-questionnaires/Pages/ default.aspx (accessed January 7, 2021).

[51] Buysse DJ, Reynolds CF, Monk TH, Berman SR, Kupfer DJ. The Pittsburgh sleep quality index: a new instrument for psychiatric practice and research. Psychiatry Res 1989;28;193-213.

[52] National Institute of Mental Health. National Mental Health Survey, Bangladesh 2018-19: Provisional Fact Sheet. Dhaka, Bangladesh: Ministry of Health and Family Welfare; 2019.

[53] Shultz JM, Baingana F, Neria Y. The 2014 Ebola outbreak and mental health: current status and recommended response. JAMA 2015;313;567-8.

[54] Cheng C. To be paranoid is the standard? Panic responses to SARS outbreak in the Hong Kong special administrative region. Asian Perspect 2004;28;67-98.

[55] Ji D, Ji YJ, Duan XZ, Li WG, Sun ZQ, Song XA, et al. Prevalence of psychological symptoms among Ebola survivors and healthcare workers during the 2014-2015 Ebola outbreak in Sierra Leone: a cross-sectional study. Oncotarget 2017;8;12784-91.

[56] Mak IWC, Chu CM, Pan PC, Yiu MGC, Ho SC, Chan VL. Risk factors for chronic post-traumatic stress disorder (PTSD) in SARS survivors. General Hosp Psychiatry 2010;32;590-8.

[57] Wasserman IM. The impact of epidemic, war, prohibition and media on suicide: United States, 1910-1920. Suicide Life Threat Behav 1992;22;240-54.

[58] Mazza C, Ricci E, Biondi S, Colasanti M, Ferracuti S, Napoli C, et al. A nationwide survey of psychological distress among Italian people during the COVID-19 pandemic: immediate psychological responses and associated factors. Int J Environ Res Public Health 2020;17;3165.

[59] Balaratnasingam S, Janca A. Mass hysteria revisited. Curr Opin Psychiatry 2006;19;171-4. 
[60] Wong TW, Gao Y, Tam WWS. Anxiety among university students during the SARS epidemic in Hong Kong. Stress Health 2007;23;31-5.

[61] Banik R, Rahman M, Sikder T, Gozal D. COVID-19 in Bangladesh: public awareness and insufficient health facility remain key challenges. Public Health 2020;183;50-1.

[62] Gritsenko V, Skugarevsky O, Konstantinov V, Khamenka N, Marinova T, Reznik A, et al. COVID 19 fear, stress, anxiety, and substance use among Russian and Belarusian university students. Int J Mental Health Addict 2020;1-7.

[63] Zhai Y, Du X. Addressing collegiate mental health amid COVID-19 pandemic. Psychiatry Res 2020;288;113003.

[64] Bontcheva K, Gorrell G, Wessels B. Social media and information overload: survey results. arXiv: 1306.0813, 2013. Available from: https://ui.adsabs.harvard.edu/abs/2013arXiv1306.0813B (accessed January 7, 2021).

[65] Choi DH, Yoo W, Noh GY, Park K. The impact of social media on risk perceptions during the MERS outbreak in South Korea. Comput Hum Behav 2017;72;422-31.

[66] Israfil Bhuiyan AKM, Sakib N, Pakpour AH, Griffiths MD, Mamun MA. COVID-19-related suicides in Bangladesh due to lockdown and economic factors: case study evidence from media reports. Int J Mental Health Addict 2020;1-6.

[67] Goyal K, Chauhan P, Chhikara K, Gupta P, Singh MP. Fear of COVID 2019: first suicidal case in India! Asian J Psychiatry 2020;49;101989.

[68] Mamun MA, Griffiths MD. First COVID-19 suicide case in Bangladesh due to fear of COVID-19 and xenophobia: possible suicide prevention strategies. Asian J Psychiatr 2020;51; 102073.

[69] Mamun MA, Ullah I. COVID-19 suicides in Pakistan, dying off not COVID-19 fear but poverty? - The forthcoming economic challenges for a developing country. Brain Behav Immun 2020;87;163-6.

[70] Cheung YT, Chau PH, Yip PSF. A revisit on older adults suicides and Severe Acute Respiratory Syndrome (SARS) epidemic in Hong Kong. Int J Geriatr Psychiatry 2008;23;1231-8.

[71] Mamun MA, Hossain MS, Griffiths MD. Mental health problems and associated predictors among Bangladeshi students. Int J Mental Health Addict 2019.

[72] Hossain S, Anjum A, Uddin ME, Rahman MA, Hossain MF. Impacts of socio-cultural environment and lifestyle factors on the psychological health of university students in Bangladesh: a longitudinal study. J Affect Disord 2019;256;393-403.

[73] Ahmed JU. Massification to marketization of higher education: private university education in Bangladesh. High Educ Future 2015;3;76-92.

[74] Ashraf MA, Ibrahim Y, Joarder MHR. Quality education management at private universities in Bangladesh: an exploratory study. J Educ Educators 2009;24;17-32.

[75] Fernandes N. Economic effects of coronavirus outbreak (COVID-19) on the world economy. IESE Business School Working Paper No. WP-1240-E. 2020.

[76] Sahoo S, Rani S, Parveen S, Singh AP, Mehra A, Chakrabarti S, et al. Self-harm and COVID-19 pandemic: an emerging concern - a report of 2 cases from India. Asian J Psychiatry 2020;51;102104. 